\title{
Embedding Information Literacy in University Curricula: Policies, Strategies and Reflective Educators
}

\author{
Anne Sissel Vedvik Tonning1, Eystein Gullbekk², Therese S. Skagen², Maria Carme Torras \\ Calvo $^{3}$ \\ ${ }^{1}$ University of Bergen; 2 University of Oslo; ${ }^{3}$ Bergen University College
}

Contact:

E-mail: post@noril.uib.no

\section{EDITORIAL}

\begin{abstract}
Developments in the field of information literacy (IL) and learning have become increasingly prominent in academic library settings. There is no lack of discussion at national and international conferences, where 'best practice' models are presented. Still, however, academic libraries in the higher education (HE) sector often struggle with actually integrating IL into university curricula. How are we to meet this challenge?
\end{abstract}

Arguably, a key question here is whether libraries in European HE can collaborate with their stakeholders and use the national qualification frameworks as a tool in embedding IL into in study programmes and courses across the HE curriculum.

Of course, the Bologna process is also about IL and learning. At the Ministerial conference in Bergen in 2005, the participating countries accepted the European Qualification Framework (EQF) with its three cycles (bachelor, master, doctoral) based on learning outcomes in HE. It was also agreed that the national qualification frameworks in the same countries should be developed and implemented by the end of 2010, and that these should be aligned to the EQF. The Norwegian Government launched the Norwegian Qualification Framework in 2009, and the HE institutions were given a deadline for the implementation of all programmes and courses at all levels by the end of 2012. Accordingly, it is not unrealistic to expect that the national qualification frameworks will emphasise IL in such a way that it can be linked to learning outcomes.

It is of great importance that HE libraries document their IL strategies and also promote their IL and learning support in dialogues with their stakeholders. To do this kind of strategic work, the librarians need to be confident about their own role as IL educators.

The three peer-reviewed articles in this issue address different levels of systemic challenge. The first is aimed at academic libraries that want to develop their services to the institution's PhD students. The second focuses on libraries and IL support at a strategic and political level. The third article aims to assist academic libraries in developing the librarian's role in IL training 
In their article, Changing Anatomies of Information Literacy at the Postgradual Level: Refinements of Models and Shifts in Assessment, Sonja Spiranec and Mihaela Banek Zorica point out several shifts that IL education needs to include in order to be relevant for postgraduate students. They argue that these shifts should be addressed in HE libraries, to pursue and develop library services that will support PhD students' learning and research.

Sirje Virkus, in her article, Information Literacy from the Policy and Strategy Perspective, reports on data collected in 2003-04, from open distance learning universities and mixed modes universities in Europe. One of Virkus' suggestions is that librarians frequently lack decisionmaking authority regarding incorporation of IL into the curriculum design. In the article Virkus presents a relevant literature review on policy and strategy aspects of IL from 2004 on. Finally, she discusses the centrality of the Bologna process to IL policy and strategy.

Andrew Whitworth's article, The Reflective Information Literacy Educator, argues that continuing professional development (CPD) of the librarian-as-educator should be anchored in educational research and theory, as well as in a reflective practice. Like Virkus, he claims that the HE librarians as a group lack "capital" to make their views heard in decision-making.

The Editors are grateful to the Editorial Board and their network for their thorough referee-work. We hope you will enjoy this issue of NORIL.

As an open access journal, NORIL is indexed in Google Scholar, and the statistics report that the articles are steadily downloaded and cited. Since the first issue in 2009, we also have signed a contract that allows EBSCO to index and distribute the articles from NORIL. We hope this will contribute to wider dissemination. Our aim is publish two issues a year in the years to come, which will ensure the regularity needed to be indexed in the database Web of Science.

The next regular issue of NORIL is scheduled for December 2012, and the deadline for submitting your paper to that issue is October $15^{\text {th }}$. Please remember that the review process does take time, and that papers are reviewed continuously, so there is no need to wait for the deadline. Finally we draw your attention to the scope of NORIL's interests, namely to contribute to a better understanding of the relationship between research-based knowledge and learning processes in HE sector, and teaching practices within the field of IL.

The next issue of NORIL will be a special issue with abstracts from the Norwegian academic librarian's conference in June this year in Kristiansand. This will be published in August. 